\title{
Retinal microvascular abnormalities and blood pressure in older people: the Cardiovascular Health Study
}

\author{
TY Wong, L D Hubbard, R Klein, E K Marino, R Kronmal, A R Sharrett, D S Siscovick, \\ G Burke, J M Tielsch
}

Br J O phthalmol 2002;86:1007-1013

See end of article for authors' affiliations

......................

Correspondence to:

Tien Yin W ong,

Department of

0 phthalmology, $\mathrm{N}$ ational

University of Singapore

10 Kent Ridge Crescent,

Singapore 119260;

ophcoty@nus.edu.sg

Accepted for publication

18 March 2002
Aim: To examine the relation between blood pressure and retinal microvascular abnormalities in older people.

Methods: The Cardiovascular Health Study is a prospective cohort study conducted in four US communities initiated in 1989 to 1990 . Blood pressure was measured according to standardised protocols at each examination. During the 1997-8 examination, retinal photographs were taken of 2405 people aged 69-97 years (2056 without diabetes and 349 with diabetes). Signs of focal microvascular abnormalities (focal arteriolar narrowing, arteriovenous nicking, and retinopathy) were evaluated from photographs according to standardised methods. To quantify generalised arteriolar narrowing, the photographs were digitised and diameters of individual arterioles were measured and summarised. Results: In non-diabetic people, elevated concurrent blood pressure taken at the time of retinal photography was strongly associated with presence of all retinal microvascular lesions. The multivariable adjusted odds ratios, comparing the highest to lowest quintile of concurrent systolic blood pressure, were $4.0(95 \%$ confidence intervals $(\mathrm{Cl}): 2.4$ to 6.9 , p test of trend $<0.001)$ for focal arteriolar narrowing, $2.9(95 \% \mathrm{Cl}: 1.6$ to $5.3, p<0.001)$ for arteriovenous nicking, $2.8(95 \% \mathrm{Cl}: 1.5$ to $5.2, p<0.001)$ for retinopathy, and $2.1(95 \% \mathrm{Cl}: 1.4$ to $3.1, p<0.001)$ for generalised arteriolar narrowing. G eneralised arteriolar narrowing and possibly arteriovenous nicking were also significantly associated with past blood pressure measured up to 8 years before retinal photography, even after adjustment for concurrent blood pressure. These associations were somewhat weaker in people with diabetes.

Conclusions: Retinal microvascular abnormalities are related to elevated concurrent blood pressure in older people. Additionally, generalised retinal arteriolar narrowing and possibly arteriovenous nicking are related to previously elevated blood pressure, independent of concurrent blood pressure. These data suggest that retinal microvascular changes reflect severity and duration of hypertension.
$R^{s}$ etinal microvascular abnormalities, such as focal and generalised arteriolar narrowing, arteriovenous nicking, and retinopathy (for example, microaneurysms and retinal haemorrhages) are seen fairly frequently in the adult population. ${ }^{1}$ Although these retinal abnormalities are long known to be associated with hypertension status and elevated blood pressure (BP), ${ }^{2-9}$ much remains to be understood regarding the nature of these associations. Studies have shown that retinal microvascular abnormalities can be detected even in people without a history of hypertension or diabetes, ${ }^{17}$ and predict incident stroke independent of measured BP levels. ${ }^{10}$ Thus, it has been suggested that some of these retinal lesions do not simply reflect current BP levels but are markers of persistent microvascular damage from hypertension. ${ }^{11}$

This hypothesis is supported by data from the Atherosclerosis Risk in Communities (ARIC) study, a large population based study of cardiovascular disease in middle aged people. The ARIC study demonstrated that generalised retinal arteriolar narrowing and arterioven ous nicking, as ascertained from retinal photographs, were strongly related not only to BP measured at the time of photography, but also independently to past BP measured 3-6 years before the photography. ${ }^{12}$ Few other population based data regarding such associations are available, particularly in older people.

The aim of this study is to examine the relation of hypertension status and concurrent and past BP to retinal microvascular abnormalities in older men and women aged 69-97 years.

\section{METHODS}

Study population

The Cardiovascular Health Study (CHS) is a population based cohort study of cardiovascular disease in adults 65 years of age and older. ${ }^{13}$ The study population and conduct are described in detail elsewhere. ${ }^{14}$ In brief, recruitment of the original cohort of 5201 people took place in 1989 to 1990 in four field centres: Allegheny County, PA, USA; Forsyth County, NC, USA; Sacramento County, CA, USA; and Washington County, MD, USA. An additional 687 eligible black people were recruited from Forsyth County, Sacramento County, and Allegheny County in 1992-3. Differences between those recruited and those not recruited have been presented el sewhere. ${ }^{14}$

Retinal photographs were offered to participants who returned for the clinic examination in 1997-8, approximately 8 years after the baseline examination. Of 4249 people ( $95.5 \%$ of survivors) who were contacted at this examination, we initially excluded 247 people with missing data for a diagnosis of diabetes mellitus ( because diabetes status may complicate the understanding of the association between BP and retinal microvascular signs). Of the remaining 4002 people, 3002 were examined at the study clinics and the other 1000 were examined at home or in nursing institutions or were contacted only by mail/phone. Retinal photographs were available for 2793 people ( 2754 were those examined at the study clinics), but could not be graded for any retinal microvascular signs in 388 people because of poor quality due to media opacities or small pupil size. Thus, 2405 people with gradable retinal photographs were available for this study. Of these, 2056 did not have diabetes and 349 had diabetes, as defined according to the American Diabetes Association criteria ${ }^{15}$ (treatment with 
Table 1 Comparison of people included and excluded who attended the 1997-8 cardiovascular health study examination

\begin{tabular}{|c|c|c|c|}
\hline & \multicolumn{2}{|c|}{ Adjusted means or percentage* } & \multirow[b]{2}{*}{$\mathrm{p}$ Value } \\
\hline & Included $(n=2405)$ & Excluded $(n=1597)$ & \\
\hline Age (years) & 78.3 & 80.7 & $<0.001$ \\
\hline W omen $(\%)$ & 60.0 & 63.6 & 0.024 \\
\hline Black $(\%)$ & 14.6 & 21.9 & $<0.001$ \\
\hline Hypertension (\%) & 59.2 & 57.5 & 0.394 \\
\hline Systolic blood pressure $(\mathrm{mm} \mathrm{Hg})$ & 132.0 & 132.9 & 0.297 \\
\hline Diastolic blood pressure $(\mathrm{mm} \mathrm{Hg})$ & 66.5 & 67.6 & 0.010 \\
\hline Fasting glucose (mg/ dl) & 101.8 & 104.4 & 0.038 \\
\hline Coronary heart disease (\%) & 24.7 & 30.9 & $<0.001$ \\
\hline Stroke $(\%)$ & 6.2 & 11.5 & $<0.001$ \\
\hline Cigarette smoking, current (\%) & 6.3 & 8.0 & 0.059 \\
\hline Alcohol consumption, current (\%) & 41.4 & 26.8 & $<0.001$ \\
\hline Total cholesterol (mg/ dl) & 202.4 & 201.7 & 0.641 \\
\hline
\end{tabular}

either oral hypoglycaemic agents and/or insulin in the year before the examination; or having a fasting blood sugar of $\geqslant 126 \mathrm{mg} / \mathrm{dl}$ for those not using any hypoglycaemic agents in the past year).

Comparisons of people with $(n=2405)$ and without $(n=$ 1597) retinal photographs or gradable photographs appear in Table 1. Not having photographs or gradable photographs was associated with increasing age, female sex, and black ethnicity. After controlling for age, sex, and race, those excluded had a significantly higher diastolic BP and fasting glucose and were more likely to have a history of coronary heart disease and stroke and to consume less alcohol.

Retinal photography and grading

Retinal photography procedures in the CHS were similar to the ARIC study, which have been previously reported in detail. ${ }^{16}$ Briefly, photographs of the retina were taken of one randomly selected eye after 5 minutes of dark adaptation and evaluated according to standardised protocols at the Fundus Photograph Reading Center, University of Madison, WI, USA by trained graders who were masked to subject identity.

Focal microvascular lesions were evaluated from the photographic slides using standardised methods. ${ }^{16}$ Focal arteriolar narrowing and arteriovenous nicking were defined as present if graded definite or probable. Retinopathy was defined as present if any of the following lesions were graded definite or probable: microaneurysms, retinal haemorrhages (blot or flame-shaped), soft exudates (cotton wool spots), hard exudates, macular oedema, intraretinal microvascular abnormalities, ven ous beading, new vessels at the disc or elsewhere, vitreous haemorrhage, disc swelling, and laser photocoagulation scars.

For the evaluation of generalised retinal arteriolar narrowing, the photographic slides were digitised with a high resolution scanner. The diameters of all arterioles and venules coursing through a specified area half to one disc diameter from the optic disc were measured on the computer. ${ }^{16}$ The individual arteriolar and venular diameters were combined into summary measures (referred to as arteriolar and venular equivalents) using formulas by Parr ${ }^{17}{ }^{18}$ and Hubbard. ${ }^{16}$ The arteriolar and venular equivalents have an approximately normal distribution, with smaller equivalents representing narrower average arteriolar and venular diameters in that eye, respectively. ${ }^{16}$

Quality control procedures were implemented during the "light box" and computer assisted grading. In the CHS, there were 71 intragrader and 69 intergrader re-readings. The intragrader kappa statistics were 0.57 for focal arteriolar narrowing, 0.49 for arteriovenous nicking, and 0.90 for retinopathy, while the intergrader kappa statistics were $0.31,0.43$, and 0.88 for the corresponding retinal lesions. For arteriolar and venular equivalents, the intragrader and intergrader intraclass correlation coefficients ranged from 0.67 to 0.91 .
Definition of hypertension status, and concurrent and past blood pressure

BP was measured annually using standardised written protocols over the study duration of 9 years $(1989-98){ }^{19}$ Hypertension status was defined at the time of retinal photography (1997-8 examination). A person was considered to have hypertension based on systolic BP $140 \mathrm{~mm} \mathrm{Hg}$ or greater, diastolic BP $90 \mathrm{~mm} \mathrm{Hg}$ or greater, or the combination of self reported high BP diagnosis and use of antihypertensive medications. A person with hypertension was further classified into mutually exclusive categories: (1) treated, controlled hypertension (using antihypertensive medications, systolic BP less than $140 \mathrm{~mm} \mathrm{Hg}$, and diastolic BP less than $90 \mathrm{~mm}$ $\mathrm{Hg}$ ), (2) treated, uncontrolled hypertension (using antihypertensive medications and systolic BP $140 \mathrm{~mm} \mathrm{Hg}$ or greater, or diastolic BP $90 \mathrm{~mm} \mathrm{Hg}$ or greater), and (3) untreated hypertension (not using antihypertensive medications and systolic BP $140 \mathrm{~mm} \mathrm{Hg}$ or greater, or diastolic BP $90 \mathrm{~mm} \mathrm{Hg}$ or greater).

We evaluated the associations between retinal lesions and concurrent and past BP. Concurrent BP was defined as values obtained at the time of retinal photography (1997-8). Past BP was defined as the average of values obtained up to 8 years before the retinal photography (1989-97).

Definitions of vascular risk factors

Participants underwent standardised assessment of cardiovascular risk factors, including examiner administered questionnaires, electrocardiography, carotid ultrasonography, echocardiography, and blood chemistry profiles, described in detail el sewhere. ${ }^{13}{ }^{20-23}$ Coronary heart disease and stroke were ascertained and classified by an adjudication process involving previous medical history, physical examination, and laboratory criteria. $^{20}$ Subclinical cardiovascular disease was defined as major electrocardiogram abnormalities, echocardiogram wall motion abnormality or low ejection fraction, increased carotid or internal carotid artery wall thickness ( $>80$ th percentile) or stenosis ( $>25$ th percentile) from vascular ultrasound examination, a decreased ankle-arm systolic BP index (less than 0.9 ), and positive responses to the Rose Questionnaire for angina or intermittent claudication. ${ }^{23}$ Blood collection and processing for fasting glucose have been previously presented. Cigarette smoking and use of antihypertensive medication were ascertained from questionnaires.

\section{Statistical methods}

We compared characteristics between people included and excluded from this study using analysis of covariance models to adjust for age, sex, and race. Focal arteriolar narrowing, 
Table 2 Retinal microvascular characteristics, by hypertension status, non-diabetic people

\begin{tabular}{|c|c|c|c|c|c|c|c|c|}
\hline & \multicolumn{2}{|c|}{ Focal arteriolar narrowing } & \multicolumn{2}{|c|}{ Arteriovenous nicking } & \multicolumn{2}{|l|}{ Retinopathy } & \multicolumn{2}{|c|}{$\begin{array}{l}\text { Generalised arteriolar } \\
\text { narrowing }\end{array}$} \\
\hline & No (\%) & OR $(95 \% \mathrm{Cl})$ & No (\%) & OR $(95 \% \mathrm{Cl})$ & No (\%) & OR $(95 \% \mathrm{Cl})$ & No (\%) & OR $(95 \% \mathrm{Cl})$ \\
\hline \multicolumn{9}{|l|}{ All people* } \\
\hline $\mathrm{N}$ ormotensive & $785(6.1)$ & 1.0 & $797(5.9)$ & 1.0 & $749(5.6)$ & 1.0 & $736(17.5)$ & 1.0 \\
\hline \multicolumn{9}{|l|}{ Hypertensive } \\
\hline Controlled & $473(5.1)$ & $0.8(0.5$ to 1.4$)$ & $486(6.6)$ & $1.1(0.7$ to 1.7$)$ & $436(6.9)$ & $1.1(0.7$ to 2.0$)$ & $438(18.9)$ & $1.1(0.8$ to 1.5$)$ \\
\hline Uncontrolled & $338(16.0)$ & $2.8(1.8$ to 4.2$)$ & $355(12.1)$ & $2.1(1.3$ to 3.2$)$ & $344(16.0)$ & $3.0(2.0$ to 4.6$)$ & $331(20.5)$ & $1.2(0.9$ to 1.7$)$ \\
\hline Untreated & $183(24.0)$ & $4.9(3.1$ to 7.7$)$ & $191(9.4)$ & $1.6(0.9$ to 2.9$)$ & $178(7.9)$ & $1.4(0.7$ to 2.6$)$ & $175(28.6)$ & $1.9(1.3$ to 2.9$)$ \\
\hline \multicolumn{9}{|c|}{ - } \\
\hline $\mathrm{N}$ ormotensive & $338(5.3)$ & 1.0 & $346(5.8)$ & 1.0 & $319(4.7)$ & 1.0 & $321(19.0)$ & 1.0 \\
\hline \multicolumn{9}{|l|}{ Hypertensive } \\
\hline Controlled & $179(1.7)$ & $0.3(0.1$ to 1.1$)$ & $186(5.9)$ & $1.0(0.5$ to 2.2$)$ & $167(1.8)$ & $0.4(0.1$ to 1.3$)$ & $166(20.5)$ & $1.1(0.7$ to 1.8$)$ \\
\hline Uncontrolled & $106(11.3)$ & $2.3(1.1$ to 4.9$)$ & $114(11.4)$ & $2.1(1.0$ to 4.3$)$ & $113(14.2)$ & $3.2(1.5$ to 6.8$)$ & $104(20.2)$ & $1.1(0.6$ to 1.9$)$ \\
\hline Untreated & $63(15.9)$ & $3.6(1.6$ to 8.4$)$ & $64(7.8)$ & $1.4(0.5$ to 3.9$)$ & $56(10.7)$ & $2.5(0.9$ to 6.7$)$ & $61(32.8)$ & $2.1(1.2$ to 3.9$)$ \\
\hline \multicolumn{9}{|l|}{ W oment } \\
\hline $\mathrm{N}$ ormotensive & $447(6.7)$ & 1.0 & $451(6.0)$ & 1.0 & $430(6.3)$ & 1.0 & $415(16.4)$ & 1.0 \\
\hline \multicolumn{9}{|l|}{ Hypertensive } \\
\hline Controlled & $294(7.1)$ & $1.1(0.6$ to 2.0$)$ & $300(7.0)$ & $1.1(0.6$ to 2.0$)$ & $269(10.0)$ & $1.7(0.9$ to 2.9$)$ & $272(18.0)$ & $1.2(0.7$ to 1.7$)$ \\
\hline Uncontrolled & $232(18.1)$ & $3.1(1.9$ to 5.2$)$ & $241(12.4)$ & $2.1(1.2$ to 3.6$)$ & $231(16.9)$ & $3.0(1.8$ to 5.1$)$ & $227(20.7)$ & $1.3(0.8$ to 1.9$)$ \\
\hline Untreated & $120(28.3)$ & $5.6(3.3$ to 9.8$)$ & $127(10.2)$ & $1.8(0.9$ to 3.5$)$ & $122(6.6)$ & $1.1(0.5$ to 2.4$)$ & $114(26.3)$ & $1.8(1.1$ to 3.0$)$ \\
\hline
\end{tabular}

$\mathrm{N}$ o (\%) represents the number of participants (prevalence of retinal microvascular lesion) within a specific hypertensive category. G eneralised arteriolar narrowing defined as the lowest quintile of the arteriolar equivalent distribution in the population.

$* 0$ dds ratio $(O \mathrm{R})$ and $95 \%$ confidence interval (CI) of retinal microvascular lesion, comparing a specific hypertensive category to normotensive, adjusted for age, sex, and race.

†O dds ratio adjusted for age and race only.

arteriovenous nicking, and retinopathy were analysed as binary variables. The retinal arteriolar and venular diameter equivalents were initially analysed as continuous variables. The retinal arteriolar equivalent was also categorised into quintiles and generalised arteriolar narrowing was defined as the lowest quintile of the arteriolar equival ent.

We used logistic regression to determine the odds ratios for a specific retinal lesion (focal arteriolar narrowing, arteriovenous nicking, retinopathy, and generalised arteriolar narrowing) by hypertension status and by quintiles or a 10 $\mathrm{mm} \mathrm{Hg}$ increase in systolic and diastolic BP. All models were adjusted for age, sex, and race. In multivariate models, we also adjusted for presence of coronary heart disease (yes, no), stroke (yes, no), subclinical cardiovascular disease (yes, no), fasting glucose $(\mathrm{mg} / \mathrm{dl})$, cigarette smoking status (ever, never), and antihypertensive medication use (yes, no). In analyses of associations for past $\mathrm{BP}$, we adjusted for concurrent BP and antihypertensive medication use (yes, no). ${ }^{12}$ We performed all analysis separately in people with and without diabetes.

To reduce the effect of magnification differences between photographs (for example, because of refractive errors), we repeated these analysis by combining the arteriolar and venular equivalents into an arteriole to venule ratio (AVR), ${ }_{16}^{16}$ with general ised arteriolar narrowing defined as the lowest quintile of the AVR. As previously reported, the AVR compensates somewhat for possible magnification differences between eyes (an AVR of 1.0 suggests that arteriolar diameters were, on average, the same as venular diameters in that eye, while smaller AVR suggests narrower arterioles). ${ }^{12}{ }^{16}$

Table 3 Retinal microvascular characteristics, by concurrent systolic blood pressure (1997-8, at the time of retinal photography), non-diabetic people

\begin{tabular}{|c|c|c|c|c|c|c|c|c|}
\hline & \multicolumn{2}{|c|}{ Focal arteriolar narrowing } & \multicolumn{2}{|c|}{ Arteriovenous nicking } & \multicolumn{2}{|l|}{ Retinopathy } & \multicolumn{2}{|c|}{$\begin{array}{l}\text { Generalised arteriolar } \\
\text { narrowing }\end{array}$} \\
\hline & No (\%) & OR $(95 \% \mathrm{Cl})$ & No (\%) & OR $(95 \% \mathrm{Cl})$ & No (\%) & OR $(95 \% \mathrm{Cl})$ & No (\%) & OR $(95 \% \mathrm{Cl})$ \\
\hline \multicolumn{9}{|c|}{ Age, sex, and race adjusted* } \\
\hline 1st quintile & $388(5.7)$ & 1.0 & $393(4.6)$ & 1.0 & $357(5.0)$ & 1.0 & $356(14.0)$ & 1.0 \\
\hline 2 nd quintile & $372(4.0)$ & $0.7(0.3$ to 1.3$)$ & $385(4.9)$ & $1.1(0.6$ to 2.1$)$ & $353(6.2)$ & $1.2(0.6$ to 2.3$)$ & $354(18.9)$ & $1.5(1.0$ to 2.2$)$ \\
\hline 3 rd quintile & $338(5.9)$ & $1.0(0.5$ to 1.8$)$ & $344(10.5)$ & $2.4(1.3$ to 4.3$)$ & $318(5.3)$ & $1.0(0.5$ to 2.0$)$ & $315(19.7)$ & $1.5(1.0$ to 2.2$)$ \\
\hline 4 th quintile & $361(14.1)$ & $2.6(1.5$ to 4.3$)$ & $375(6.1)$ & $1.3(0.7$ to 2.5$)$ & $357(10.9)$ & $2.2(1.2$ to 3.9$)$ & $341(22.6)$ & $1.7(1.2$ to 2.6$)$ \\
\hline 5 th quintile & $320(19.4)$ & $\begin{array}{l}3.7(2.2 \text { to } 6.2) \\
p<0.001 \ddagger\end{array}$ & $332(13.3)$ & $\begin{array}{l}3.0(1.7 \text { to } 5.4) \\
p<0.001 \ddagger\end{array}$ & $322(14.0)$ & $\begin{array}{l}2.8(1.6 \text { to } 5.0) \\
p<0.001 \neq\end{array}$ & $314(23.6)$ & $\begin{array}{l}1.9(1.3 \text { to } 2.9) \\
p=0.001 \neq\end{array}$ \\
\hline \multicolumn{9}{|c|}{ Multivariable adjusted $\dagger$} \\
\hline 1st quintile & $368(6.0)$ & 1.0 & $374(4.8)$ & 1.0 & $341(4.7)$ & 1.0 & $338(14.2)$ & 1.0 \\
\hline 2 nd quintile & $356(4.2)$ & $0.7(0.3$ to 1.3$)$ & $368(4.6)$ & $1.0(0.5$ to 1.9$)$ & $340(6.2)$ & $1.3(0.7$ to 2.5$)$ & $340(18.5)$ & $1.4(0.9$ to 2.1$)$ \\
\hline 3 rd quintile & $323(6.2)$ & $1.0(0.5$ to 1.9$)$ & $329(10.0)$ & $2.2(1.2$ to 4.0$)$ & $305(5.6)$ & $1.1(0.5$ to 2.3$)$ & $301(20.6)$ & 1.5 (1.0 to 2.3$)$ \\
\hline 4 th quintile & $344(14.0)$ & $2.5(1.5$ to 4.3$)$ & $357(5.9)$ & $1.2(0.6$ to 2.4$)$ & $340(11.2)$ & $2.3(1.3$ to 4.3$)$ & $322(22.7)$ & $1.7(1.2$ to 2.6$)$ \\
\hline 5 th quintile & $303(19.8)$ & $\begin{array}{l}4.0(2.4 \text { to } 6.9) \\
p<0.001 \neq\end{array}$ & $314(13.1)$ & $\begin{array}{l}2.9(1.6 \text { to } 5.3) \\
p<0.001 \ddagger\end{array}$ & $308(14.0)$ & $\begin{array}{l}2.8(1.5 \text { to } 5.2) \\
p<0.001 \neq\end{array}$ & $296(24.7)$ & $\begin{array}{l}2.1(1.4 \text { to } 3.1) \\
p<0.001 \neq\end{array}$ \\
\hline
\end{tabular}

$\mathrm{N}$ o (\%) represents number of participants (proportion with retinal lesions) by BP quintile. In multivariate models, numbers are reduced due to missing covariate data. G eneralised arteriolar narrowing defined as the lowest quintile of the arteriolar equivalent distribution in the population.

$* 0$ dds ratio $(\mathrm{OR})$ and $95 \%$ confidence interval $(\mathrm{CI})$ of retinal microvascular lesion, comparing a specific BP quintile versus the 1 st, adjusted for age, sex, and race.

†Additional adjustment for presence of coronary heart disease, stroke, subclinical cardiovascular disease, fasting glucose, smoking, and antihypertensive medication use.

$\ddagger p$ Value represents test of increasing trend over BP quintiles. 

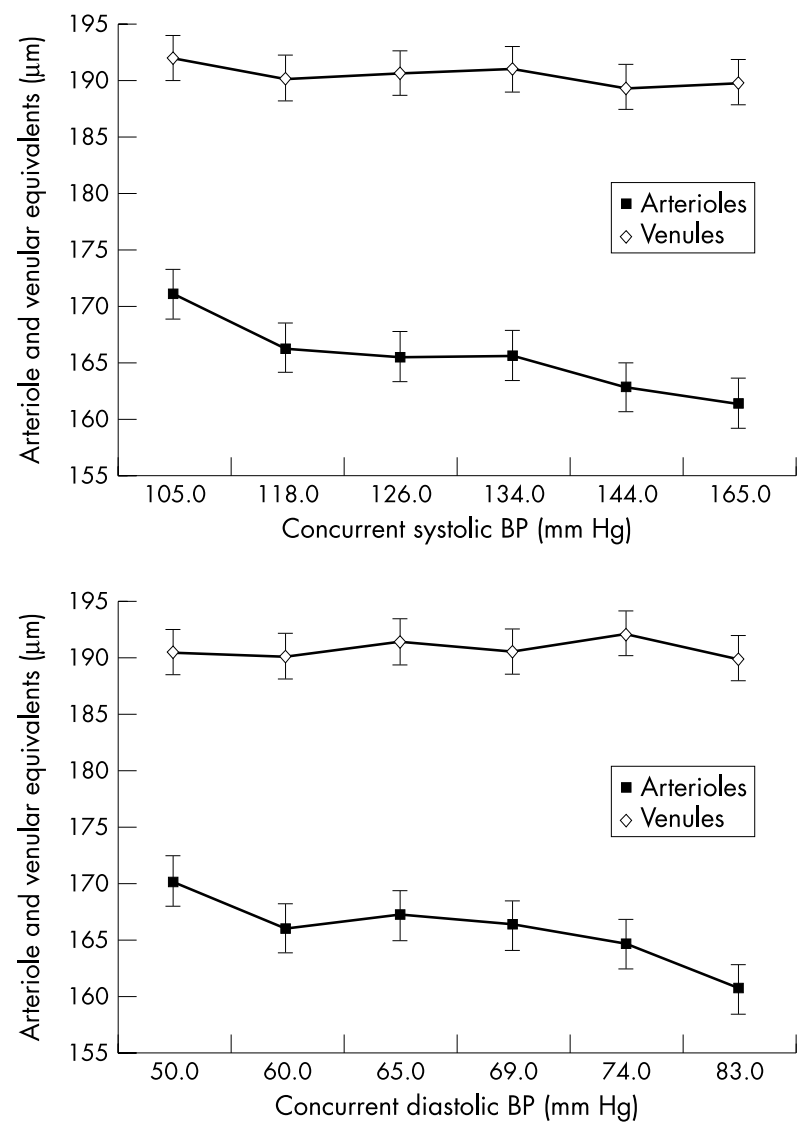

Figure 1 Retinal arteriolar and venular diameters, by concurrent systolic and diastolic blood pressure (BP), adjusted for age, sex, and race, in non-diabetic people.

\section{RESULTS}

Among people without diabetes $(n=2056)$, retinal microvascular lesions were more frequent in those with hypertension, particularly those with treated but uncontrolled hypertension and those with untreated hypertension, than people without hypertension or with treated and controlled hypertension (Table 2). Compared to people without hypertension, the age, sex, and race adjusted odds ratios for treated but uncontrolled hypertension ranged from 1.2 for generalised arteriolar narrowing to 3.0 for retinopathy, while the odds ratios for untreated hypertension ranged from 1.4 for retinopathy to 4.9 for focal arteriolar narrowing. The pattern of associations was largely similar in men and women.

All retinal microvascular lesions were monotonically associated with concurrent systolic BP. The age, sex, and race adjusted odds ratios, comparing the highest to lowest systolic BP quintiles, ranged from 1.9 for generalised arteriolar narrowing to 3.7 for focal arteriolar narrowing (Table 3). These associations were not altered in multivariate analyses adjusting for presence of cardiovascular diseases, cigarette smoking, fasting glucose, and other variables. Associations for concurrent diastolic BP were similar (data not shown).

Figure 1 shows the relation between arteriolar and venular diameter equivalents and concurrent systolic and diastolic BP. Arteriolar diameter equivalents decreased with increasing concurrent systolic and diastolic BP ( $p<0.001$ for both), suggesting that retinal arterioles were progressively narrower in those with higher BP. In contrast, venular diameter equivalent was not much changed with BP.

The relations between each retinal lesion and a $10 \mathrm{~mm} \mathrm{Hg}$ increase in concurrent and past BP are shown in Table 4. All retinal microvascular lesions were associated with elevated concurrent $\mathrm{BP}$, with adjusted odds ratio ranging from 1.11 to 1.31 and 1.17 to 1.66 , for each $10 \mathrm{~mm} \mathrm{Hg}$ increase in concurrent systolic and diastolic BP, respectively. Additionally, general ised arteriolar narrowing, but not other retinal lesions, was also significantly associated with past systolic (odds ratio of $1.11, p=0.008$ ) and diastolic BP (odds ratio of $1.27, p=0.013$ ) measured up to 8 years before retinal photography, even after adjustment for concurrent BP measurements and use of antihypertensive medication.

We repeated analyses in people with diabetes $(n=343)$. In general, although the associations were somewhat weaker in people with diabetes than in those without, the overall direction and pattern were similar (odds ratio for retinal lesions associated with a $10 \mathrm{~mm} \mathrm{Hg}$ increase in concurrent systolic BP in people with and without diabetes are shown in Fig 2). Similarly, analyses stratified by age group (69-79 versus 80

Table 4 Retinal microvascular characteristics, per $10 \mathrm{~mm} \mathrm{Hg}$ increase in concurrent and past systolic and diastolic blood pressure, non-diabetic people

\begin{tabular}{|c|c|c|c|c|}
\hline & $\begin{array}{l}\text { Focal arteriolar } \\
\text { narrowing }\end{array}$ & Arteriovenous nicking & Retinopathy & $\begin{array}{l}\text { Generalised arteriolar } \\
\text { narrowing }\end{array}$ \\
\hline & OR $(95 \% \mathrm{Cl})^{*}$ & OR $(95 \% \mathrm{Cl})^{*}$ & OR $(95 \% \mathrm{Cl})^{*}$ & OR $(95 \% \mathrm{Cl})^{*}$ \\
\hline Concurrent systolic BP, per $10 \mathrm{~mm} \mathrm{Hg}$ increase & $\begin{array}{l}1.31(1.21 \text { to } 1.42) \\
p<0.001\end{array}$ & $\begin{array}{l}1.21(1.11 \text { to } 1.32) \\
p<0.001\end{array}$ & $\begin{array}{l}1.23(1.13 \text { to } 1.34) \\
p<0.001\end{array}$ & $\begin{array}{l}1.11(1.04 \text { to } 1.18) \\
p=0.001\end{array}$ \\
\hline Past systolic $B P$, per $10 \mathrm{~mm} \mathrm{Hg}$ increase & $\begin{array}{l}1.27(1.15 \text { to } 1.40) \\
p<0.001\end{array}$ & $\begin{array}{l}1.25(1.12 \text { to } 1.38) \\
p<0.001\end{array}$ & $\begin{array}{l}1.26(1.13 \text { to } 1.39) \\
p<0.001\end{array}$ & $\begin{array}{l}1.15(1.07 \text { to } 1.24) \\
p<0.001\end{array}$ \\
\hline Adjusted for concurrent systolic BP† & $\begin{array}{l}1.09(0.95 \text { to } 1.26) \\
p=0.208\end{array}$ & $\begin{array}{l}1.15(1.00 \text { to } 1.32) \\
p=0.057\end{array}$ & $\begin{array}{l}1.07(0.93 \text { to } 1.23) \\
p=0.382\end{array}$ & $\begin{array}{l}1.11(1.04 \text { to } 1.27) \\
p=0.008\end{array}$ \\
\hline Concurrent diastolic BP, per $10 \mathrm{~mm} \mathrm{Hg}$ increase & $\begin{array}{l}1.66(1.41 \text { to } 1.95) \\
p<0.001\end{array}$ & $\begin{array}{l}1.29(1.09 \text { to } 1.52) \\
p=0.003\end{array}$ & $\begin{array}{l}1.08(0.92 \text { to } 1.28) \\
p=0.340\end{array}$ & $\begin{array}{l}1.17(1.04 \text { to } 1.31) \\
p=0.010\end{array}$ \\
\hline Past diastolic BP, per $10 \mathrm{~mm} \mathrm{Hg}$ increase & $\begin{array}{l}1.53(1.25 \text { to } 1.88) \\
p<0.001\end{array}$ & $\begin{array}{l}1.37(1.11 \text { to } 1.69) \\
p=0.004\end{array}$ & $\begin{array}{l}1.05(0.85 \text { to } 1.30) \\
p=0.623\end{array}$ & $\begin{array}{l}1.30(1.12 \text { to } 1.50) \\
p=0.001\end{array}$ \\
\hline Adjusted for concurrent diastolic BP† & $\begin{array}{l}1.09(0.84 \text { to } 1.42) \\
p=0.522\end{array}$ & $\begin{array}{l}1.20(0.91 \text { to } 1.57) \\
p=0.204\end{array}$ & $\begin{array}{l}0.90(0.69 \text { to } 1.18) \\
p=0.439\end{array}$ & $\begin{array}{l}1.27(1.05 \text { to } 1.54) \\
p=0.013\end{array}$ \\
\hline
\end{tabular}

Concurrent systolic BP represents values taken in 1997-8 (at the time of retinal photography). Past systolic BP are values averaged over 1989-97 (1-8 years before photography). G eneralised arteriolar narrowing defined as the lowest quintile of the arteriolar equivalent distribution in the population.

$* 0$ dds ratio $(O R)$ and $95 \%$ confidence interval $(\mathrm{Cl})$ of retinal microvascular lesion, per $10 \mathrm{~mm} \mathrm{Hg}$ increase in BP, adjusted for age, sex, and race. $\dagger$ Additional adjustment for concurrent BP and antihypertensive medication use. 


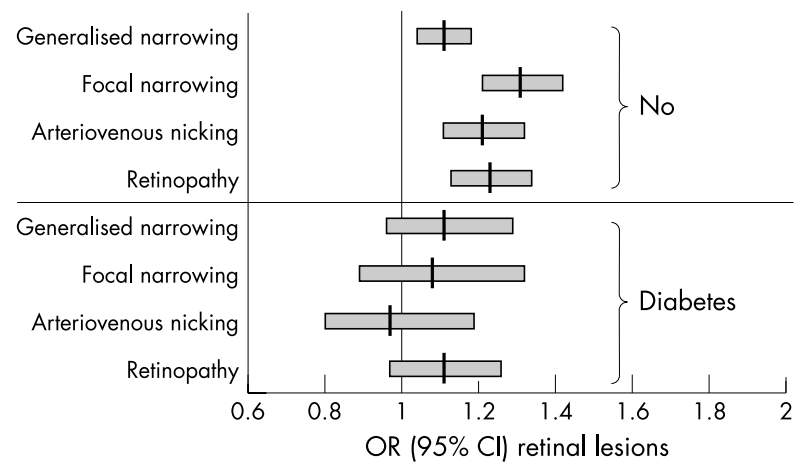

Figure 2 Odds ratio (O R) and $95 \%$ confidence interval $(95 \% \mathrm{Cl}$ ) for retinal lesions, per $10 \mathrm{~mm} \mathrm{Hg}$ increase in concurrent systolic BP, in people with and without diabetes.
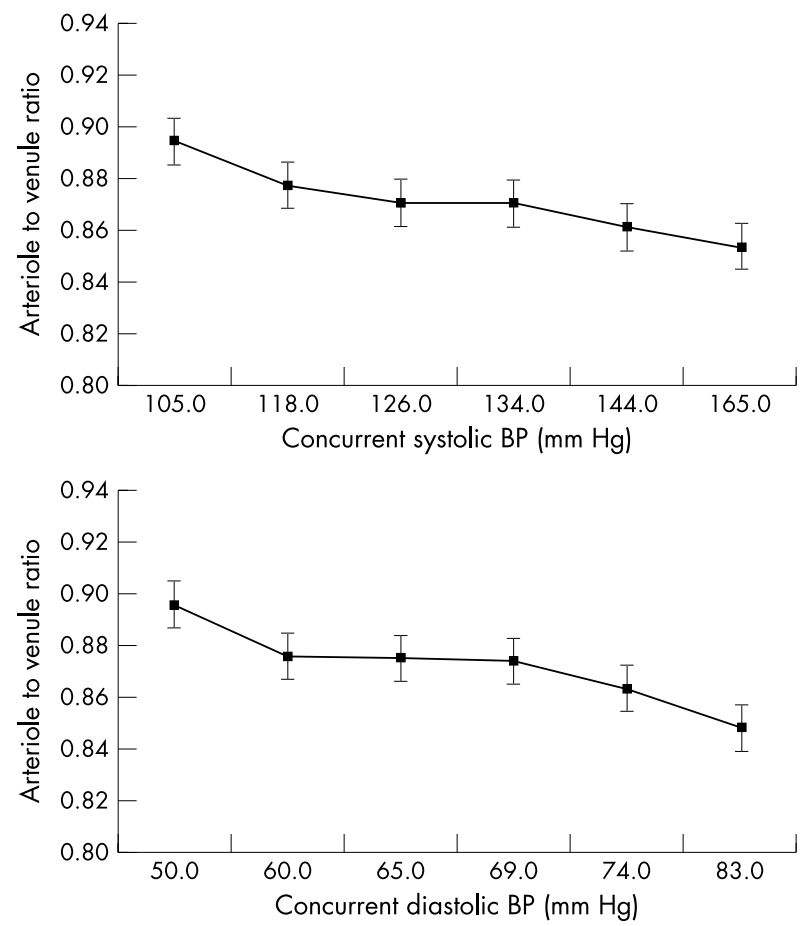

Figure 3 Retinal arteriole to venule ratio, by concurrent systolic and diastolic blood pressure, adjusted for age, sex, and race, in non-diabetic people.

and older), sex, and race did not substantially alter the results (data not shown).

Finally, we examined the relations of the ratio of arteriolar and venular diameter equivalents (AVR) to systolic and diastolic BP (Fig 3). After adjusting for age, sex, and race, the AVR decreased with increasing concurrent systolic and diastolic BP, suggesting that retinal arterioles were progressively narrower, compared to venules, with increasing levels of BP. When we repeated all analysis with generalised arteriolar narrowing defined as the lowest quintile of the AVR, similar results as those described were found (data not shown).

\section{DISCUSSION}

Routine retinal evaluation to detect signs of retinopathy in people with hypertension is recommended for the purpose of cardiovascular risk stratification. ${ }^{24} \mathrm{H}$ owever, the utility of such an evaluation is dependent on a clear understanding of the relation between hypertension status, BP, and retinal microvascular abnormalities lesions. Our current study provides important insights into these associations in a population based sample of older men and women aged 69-97 years. Firstly, we showed that people with poorly controlled or untreated hypertension were at the highest risk of having retinal microvascular abnormalities. Secondly, we found strong and graded associations between elevated BP and retinal microvascular abnormalities that were independent of the presence or absence of subclinical and clinical cardiovascular disease, cigarette smoking, fasting glucose, and use of antihypertensive medication. Finally, we demonstrated that generalised arteriolar narrowing, as ascertained from a quantitative assessment of arteriolar diameters from digitised retinal photographs, appears to be independently associated with past BP measured up to 8 years before the photography.

The association between hypertension status and retinal microvascular lesions in the CHS population is comparable with previous clinic based, ${ }^{2-4}$ and population based ${ }^{5-9}$ studies in younger people. Our study adds to these data by showing that among hypertensive people, those whose BP was uncontrolled despite treatment or who were not on treatment were more likely to have retinal microvascular lesions than those with good BP control. This pattern has also been observed in two previous population based studies that also used retinal photographic grading to define microvascular lesions. In the Beaver Dam Eye Study, non-diabetic people aged 43-84 years with untreated or uncontrolled hypertension were significantly more likely to have focal arteriolar narrowing, arteriovenous nicking, and retinopathy than those with hypertension with adequate BP control. ${ }^{7}$ Similarly, in the Blue Mountains Eye Study, non-diabetic people aged 49 years and older with untreated or uncontrolled hypertension were more likely to have retinopathy than those with controlled hypertension. ${ }^{25}$ Since retinal microvascular lesions are correlated with end organ damage elsewhere ${ }^{26}$ and independently predict stroke, ${ }^{10}$ these data further support the importance of appropriate BP control in reducing hypertensive associated complications.

A central question has been whether some retinal characteristics, as detected clinically, reflect transient effects of elevated BP or are markers of cumulative damage from hypertension. ${ }^{1}$ To address this, we examined their associations with concurrent and with past BP. We found that generalised arteriolar narrowing was independently related to both concurrent and past BP, which is consistent with histopathological data that show retinal arteriolar narrowing results from intimal thickening and medial hyperplasia, hyalinisation, and sclerosis of arteriolar walls. ${ }^{11}$ Arteriovenous nicking was associated independently with concurrent BP and possibly past systolic BP $(p=0.057)$. In contrast, focal arteriolar narrowing and retinopathy were related only to concurrent BP. These results are supported by data from the ARIC study that also show associations between generalised arteriolar narrowing (detected using an identical method from digitised photographs) and arteriovenous nicking with past BP measured 3-6 years before photography, despite adjustment for concurrent $\mathrm{BP}^{12}$ Thus, both the CHS and the ARIC data support the concept that generalised arteriolar narrowing and possibly arteriovenous nicking are markers of persistent arteriolar damage from hypertension, whereas focal narrowing and retinopathy reflect more transient effects of current BP levels.

It is interesting that people with the highest quintile of blood pressure were only 1.9 times more likely to have generalised retinal arteriolar narrowing than those with the lowest quintile of blood pressure (see Table 3 ), suggesting that many people with higher blood pressure may not have generalised arteriolar narrowing and, conversely, many with lower blood pressure may have some degree of arteriolar narrowing. This finding is consistent with observations by Leishman ${ }^{3}$ and Schei $^{4}$ that generalised retinal arteriolar narrowing results from a combination of hypertension and arteriolosclerosis.

We found slightly weaker associations between concurrent $\mathrm{BP}$ and the presence of retinal microvascular abnormalities in 
people with diabetes (see Fig 2). This was somewhat unexpected, and appears contrary to research indicating that BP control is particularly important in reducing the risk of diabetic retinopathy. ${ }^{27}{ }^{28}$ However, sel ective mortality may have affected these associations since it is known that among people with diabetes, those with elevated BP and retinopathy have higher mortality rates. ${ }^{29}$ Another possible explanation is that diabetes and glucose affects the physiology and anatomy of the retinal microcirculation, ${ }^{30}{ }^{31}$ which may mask potential associations between BP and the presence of retinal abnormalities. In any case, differences between people with and without diabetes were modest and not statistically significant.

Of all the hypertensive retinal changes, generalised arteriolar narrowing has traditionally been the most difficult to diagnose either clinically or from standard grading of retinal photographs. ${ }^{1}$ In the CHS and the ARIC study, we developed a new approach to quantify its presence and severity by measuring diameters of retinal arterioles on digitised photographs. For analytical purposes, we defined generalised narrowing as arteriolar equivalent values falling within the lowest quintile or 20th percentile of the population distribution. An important consideration was whether potential magnification differences between photographs resulted in substantial bias in this definition (for example, vessel calibre may be artificially magnified in photographs of myopic eyes). One approach we had previously used was to combine the arteriolar and venular diameter equivalents into a ratio (the AVR), since retinas with artificially "magnified" arterioles can be expected to have "magnified" venules. ${ }^{16}$ A smaller AVR therefore indicates a narrower arterioles with respect to venules. Overall, we found no substantial difference in the association between arteriolar diameters equivalent (Fig 1) or the AVR (Fig 3) and BP. Although the AVR is understood to represent generalised arteriolar narrowing and appears to independently predict stroke, ${ }^{10}$ caution is advised regarding the use of a ratio to infer relations about its components (that is, use of the AVR to understand relations about arteriolar diameters), since spurious correlations can result. ${ }^{32}$

What are the clinical implications of the study? The strong associations between elevated blood pressure and the occurrence of retinal microvascular abnormalities in this study appear to support the current recommendations for routine retinal evaluation in people with hypertension. ${ }^{24} \mathrm{H}$ owever, the retinal changes in the CHS were documented using standardised photographic and computer based grading methods. It is likely that direct ophthalmoscopy by family physicians or internists will be even more imprecise for detecting these lesions. ${ }^{33}$ Thus, it remains uncertain that a clinical retinal evaluation in people with hypertension is useful. A more immediate impact of our study findings lies in its relevance to cardiovascular research. Recent studies have suggested that an assessment of the retinal microvasculature and its changes from photographs may provide critical insights into the contribution of microvascular processes to the risk of stroke, ${ }^{10}$ coronary heart disease ${ }^{34}$ and cognitive impairment. ${ }^{35}$

There are several limitations of this study. Firstly, selective mortality may have obscured some relevant associations and enhanced others. Retinal photography was obtained approximately 9 years after the baseline and it is possible that hypertensive participants with retinal abnormalities are more likely to die during this period, which would mask possible associations between some lesions (for example, focal arteriolar narrowing) and BP. Secondly, the CHS did not employ pharmacological pupillary dilatation before photography and used nonstereoscopic retinal photograph of only one eye to determine the presence of retinal microvascular abnormalities. As a result, there may be more variability in the grading of specific lesions, compared to grading of stereoscopic retinal photographs of two eyes taken through dilated pupils in the Beaver Dam Eye Study. ${ }^{6}$ For example, the reproducibility of the grading of focal arteriolar narrowing was only "fair to moderate" (based on the scale proposed by Landis and $\mathrm{Koch}^{36}$ ) and could be further improved. In fact, the imprecision may have resulted in some attenuation of the association between blood pressure and the retinal microvascular changes. Thirdly, since hypertension is strongly associated with the occurrence of retinal microvascular changes, it is possible that adjusting for concurrent BP may not be sufficient to remove its impact on the past BP associations (for example, residual confounding from concurrent BP may explain the association between past BP and generalised arteriolar narrowing). However, the consistency of the results with the ARIC study makes this less likely. Finally, these analyses were cross sectional and it is impossible to distinguish cause (for example, past BP) and effect (for example development of generalised arteriolar narrowing)

Retinal microvascular changes have recently been shown to predict stroke, ${ }^{10}$ independent of measured BP and other cardiovascular risk factors. Our data suggest that general ised arteriolar narrowing and possible arteriovenous nicking reflect persistent arteriolar damage from hypertension, which provides a possible explanation for their independent associations with stroke. These data further suggest that a quantitative assessment of retinal microvascular changes using standardised photographic techniques, including computer assisted measurements of arteriolar narrowing, may provide important information in understanding the microvascular processes associated with the development of cardiovascular diseases.

\section{ACKNOWLEDGEMENT}

Supported by National Heart, Lung and Blood Institute Cardiovascular Health Study contract (NHLBI HC-97-06) and the American Diabetes Association (TYW).

\section{Authors' affiliations}

TY Wong, Department of $O$ phthalmology, $N$ ational University of Singapore and Singapore Eye Research Institute, Singapore TY Wong, L D Hubbard, R Klein, Department of O phthalmology, University of W isconsin, Madison, W I, USA

E K Marino, R Kronmal, CHS Coordinating Center, Department of Biostatistics, University of W ashington, Seattle, W A, USA

A R Sharrett, Division of Epidemiology and Clinical Applications,

N HLBI, N IH, Bethesda, M D, USA

D S Siscovick, Department of M edicine, University of W ashington, Seattle, W A, USA

G Burke, Department of Public Health Sciences, W ake Forest School of Medicine, W inston-Salem, N C, USA

J M Tielsch, Department of International Health, Johns Hopkins

Bloomberg School of Public Health, Baltimore, MD, USA

\section{REFERENCES}

1 Wong TY, Klein R, Klein BEK, et al. Retinal microvascular abnormalities and their relations with hypertension, cardiovascular diseases and mortality. Surv O phthalmol 2001;46:5980.

2 Wagener HP, Clay GE, G ipner JF. Classification of retinal lesions in the presence of vascular hypertension. Trans Am 0 phthalmol Soc $1947 ; 45: 57-73$.

3 Leishman R. The eye in general vascular disease: hypertension and arteriosclerosis. Br J O phthalmol 1957;41:641-701.

4 Scheie HG. Evaluation of ophthalmoscopic changes of hypertension and arteriolar sclerosis. Arch O phthalmol 1953;49:117-138.

5 Svardsudd $K$, W edel $H$, Aurell $E$, et al. Hypertensive eye ground changes: prevalence, relation to $\mathrm{BP}$ and prognostic importance. Acta Med Scand 1978;204:159-67.

6 Klein R, Klein BEK, Moss SE, et al. Blood pressure, hypertension and retinopathy in a population. Trans Am O phthalmol SoC 1993;91:207-22

7 Klein R, Klein BEK, M oss SE, et al. Hypertension and retinopathy, arteriolar narrowing, and arteriovenous nicking in a population. Arch O phthalmol 1994:112:92-8.

8 Klein R, Klein BEK, M OSS SE. The relation of systemic hypertension to changes in the retinal vasculature. The Beaver Dam Eye Study. Trans Am O phthalmol Soc 1997;95:329-50.

9 Klein R, Sharrett AR, Klein BEK, et al. A re retinal arteriolar abnormalities related to atherosclerosis? The Atherosclerosis Risk in Communities Study. Arterioscler Thromb Vasc Biol. 2000;20:1644-50. 
10 Wong TY, Klein R, Couper DJ, et al. Retinal microvascular abnormalities and incident strokes. The Atherosclerosis Risk in the Communities Study. Lancet 2001;358:1134-40.

11 Tso MOM, Jampol LM. Pathophysiology of hypertensive retinopathy. O phthalmology 1982;89:1132-45.

12 Sharrett AR, Hubbard LD, Cooper LS, et al Retinal arteriolar diameters and elevated blood pressure: the Atherosclerosis Risk in Communities Study. Am J Epidemiol 1999;150:263-70.

13 Fried LP, Borhani N O, Enright $P$, et al. The Cardiovascular Health Study: design and rationale. Ann Epidemiol 1991;1:263-76.

14 Tell GS, Fried LP, Hermanson B, et al. Recruitment of adults 65 years and older as participants in the Cardiovascular Health Study. Ann Epidemiol 1993;3:358-66

15 American Diabetes Association. Cclinical practice recommendations 1997. Diabetes Care 1997;20(Suppl 1):S1-70.

16 Hubbard LD, Brothers RJ, King W N , et al. M ethods for evaluation of retinal microvascular abnormalities associated with hypertension/ sclerosis in the Atherosclerosis Risk in Communities (ARIC) Study. O phthalmology 1999;106:2269-80

17 Parr JC, Spears G FS. G eneral caliber of the retinal arteries expressed as the equivalent width of the central retinal artery. $\mathrm{Am} / 0$ phthalmol 1974:472-7

18 Parr JC, Spears G FS:M athematic relationships between the width of a retinal artery and the widths of its branches. Am J O phthalmol 1974:478-83

19 Tell GS, Rutan GH, Kronmal RA, et al. Correlates of blood pressure in community-dwelling older adults. The Cardiovascular Health Study. Cardiovascular Health Study (CHS) Collaborative Research G roup. Hypertension 1994:23:59-67.

20 Psaty BM, Kuller LH, Bild D, et al. M ethods of assessing prevalent cardiovascular disease in the Cardiovascular Health Study. Ann Epidemiol 1995;5:270-7.

21 O'Leary DH, Polak JF, Kronmal RA, et al. Carotid-artery intima and media thickness as a risk factor for myocardial infarction and stroke in older adults. Cardiovascular Health Study Collaborative Research G roup. $N$ EnglJ Med 1999;340:14-22.

22 Robbins J, W ahl P, Savage P, et al. Hematological and biochemical laboratory values in older Cardiovascular Health Study participants. J Am Geriatr Soc 1995:43:855-9.
23 Kuller L Borhani N, Furberg C et al. Prevalence of subclinical atherosclerosis and cardiovascular disease and association with risk factors in the Cardiovascular Health Study. Am J Epidemiol 1994;139:1164-79.

24 J oint National Committee on the Prevention, Detection, Evaluation, and Treatment of High Blood Pressure. Sixth Report. N IH publication no 98-4080, 1997

$25 \mathrm{Yu} \mathrm{T}, \mathrm{M}$ itchell P, Berry G, et al. Retinopathy in older persons without diabetes and its relationship to hypertension. Arch 0 phthalmol 1998;116:83-9

26 Breslin DJ, Gifford RW Jr, Fairbairn JF II, et al. Prognostic importance of ophthalmoscopic findings in essential hypertension. JAM A 1966;195:335-8

27 Klein R, M oss SE, Klein BE, et al. Relation of ocular and systemic factors to survival in diabetes. Arch Intern Med 1989;149:266-72

28 Tooke JE. Microvascular function in human diabetes. A physiological perspective. Diabetes 1995;44:721-6.

29 Caballero $A E$, A rora $S$, Sa ouaf $R$, et al. Microvascular and macrovascular reactivity is reduced in subjects at risk for type 2 diabetes. Diabetes 1999;48:1856-62

30 Klein $\mathrm{BE}$, Klein $\mathrm{R}$, M OSS SE, et al. A cohort study of the relationship of diabetic retinopathy to blood pressure. Arch 0 phthalmol 1995;113:601-6.

31 UK Prospective Diabetes Study Group. Tight blood pressure contro and risk of macrovascular and microvascular complications in type 2 diabetes:UKPDS 38. BMJ 1998;317:703-13.

32 Kronmal RA. Spurious correlation and the fallacy of the ratio standard revisited. J R Stat Soc 1993;156:379-92

33 Dimmitt SB, W est JN, Eames SM, et al. Usefulness of ophthalmoscopy in mild to moderate hypertension. Lancet 1989;1:1103-6.

34 Wong TY, Klein R, Sharrett AR, et al. Retinal arteriolar narrowing and risk of coronary heart disease in men and women. The A therosclerosis Risk in Community Study. JAMA 2002;287:1153-9.

35 Wong TY, Klein R, Sharrett AR, et al. Retinal microvascular abnormalities and cognitive impairment in middle-aged persons. The Atherosclerosis Risk in the Communities Study. Stroke 2002;33:1487-92

36 Landis JR, Koch G G. The measurement of observer agreement for categorical data. Biometrics 1977;33:159-74.

Clinical Evidence-Call for contributors

Clinical Evidence is a regularly updated evidence based journal available world wide both as a paper version and on the internet. Clinical Evidence urgently needs to recruit a number of new contributors. Contributors a re health care professionals or epidemiologists with experience in evidence based medicine and the ability to write in a concise and structured way.

We are presently interested in finding contributors with an interest in the following clinical areas:

Acute bronchitis

Hepatitis B

Acute sinusitis Hepatitis C

Cataract HIV

Genital warts

Being a contributor involves:

- Appraising the results of literature searches (performed by our Information Specialists) to identify high quality evidence for inclusion in the journal.

- Writing to a highly structured template (about 1500-3000 words), using evidence from selected studies, within 6-8 weeks of receiving the literature search results.

- W orking with Clinical Evidence Editors to ensure that the text meets rigorous epidemiological and style standards.

- Updating the text every eight months to incorporate new evidence.

- Expanding the topic to include new questions once every 12-18 months.

If you would like to become a contributor for Clinical Evidence or require more information about what this involves please send your contact details and a copy of your CV, clearly stating the clinical area you are interested in, to Polly Brown (pbrown@bmjgroup.com). 